\title{
Two different pathogenic gene mutations coexisted in the same hereditary spherocytosis family manifested with heterogeneous phenotypes
}

Hongwei Shen ${ }^{1}$, Hui Huang ${ }^{2}$, Kaizhong Luo ${ }^{3}$, Yan Yi ${ }^{4^{*}}$ (D) and Xiaoliu Shi ${ }^{5^{*}}$

\begin{abstract}
Background: Hereditary spherocytosis (HS) is a common type of hereditary hemolytic anemia. According to the current diagnostic criteria of HS, patients with a family history of HS, typical clinical features and laboratory investigations could be diagnosed without the requirement of any additional tests, including genetic analysis. However, the clinical heterogeneities incur difficulties in HS diagnosis. We therefore aimed to investigate the application of genetic diagnosis in a family-based cohort.

Case presentation: In the present Chinese family, two probands sharing similar clinical manifestations, including jaundice, cholelithiasis, splenomegaly and spherocytes, while the clinical features of other family members were inconclusive. Whole-exome sequencing (WES) unexpectedly unveiled two separate disease-causing mutations in the two probands. SPTB R1625X mutation detected in proband D was a de novo mutation; while proband W inherited the SLC4A1 C.G1469A mutation from her mother, which was also inherited by her brother. However, the clinical features of proband $W$ and her mother and brother were discrepant: proband $W$ suffered from significant splenomegaly, jaundice and cholelithiasis, which resulted in cholecystectomy and splenectomy; while her mother and brother's HS were not complicated by cholelithiasis, and their splenomegaly and elevated serum bilirubin were moderate. In addition, additional genomic defects involved with HS-related symptoms have not been detected in this family.
\end{abstract}

Conclusions: Both genotypes and phenotypes could be heterogeneous in the same HS family. The analysis of pathogenic gene mutations may endeavor to play an indispensable role in the accurate diagnosis and genetic consultation of HS individuals and their family members.

Keywords: Hereditary spherocytosis, Genetic diagnosis, Whole-exome sequencing, Heterogeneous genotype, Heterogeneous phenotype

\footnotetext{
* Correspondence: yiyancsu@csu.edu.cn; shixl6@csu.edu.cn

${ }^{4}$ Department of Hematology, The Second Xiangya Hospital, Central South University, 139 Middle Renmin Road, Changsha, Hunan Province 410011, People's Republic of China

${ }^{5}$ Department of Medical Genetics, The Second Xiangya Hospital, Central South University, 139 Middle Renmin Road, Changsha, Hunan Province 410011, People's Republic of China

Full list of author information is available at the end of the article
}

(c) The Author(s). 2019 Open Access This article is distributed under the terms of the Creative Commons Attribution 4.0 International License (http://creativecommons.org/licenses/by/4.0/), which permits unrestricted use, distribution, and reproduction in any medium, provided you give appropriate credit to the original author(s) and the source, provide a link to the Creative Commons license, and indicate if changes were made. The Creative Commons Public Domain Dedication waiver (http://creativecommons.org/publicdomain/zero/1.0/) applies to the data made available in this article, unless otherwise stated. 


\section{Background}

Hereditary spherocytosis (HS) is a common type of hereditary hemolytic anemia in all racial and ethnic groups and is characterized by the presence of spherical-shaped erythrocytes (spherocytes) on the peripheral blood smear [1]. The clinical manifestations of typical HS include hemolytic anemia, jaundice, splenomegaly and cholelithiasis [1]. According to the diagnostic criteria of HS, patients with a family history of HS, typical clinical features and laboratory investigations (spherocytes, raised mean corpuscular hemoglobin concentration [MCHC], reticulocytosis) could be diagnosed without the requirement of any additional tests [2]. However, the HS clinical spectrum ranges widely from an almost silent phenotype to severe life-threatening anemia, significant splenomegaly, or extreme hyperbilirubinemia, even in the same family $[1,2]$. The clinical heterogeneities incur difficulties in HS diagnosis. Additionally, definitive diagnosis may be difficult when testing results are not consistent or conclusive $[3,4]$.

HS is usually inherited in an autosomal dominant manner. Pathogenic mutations involve the ankyrin 1 (ANK1) gene on chromosome $8 \mathrm{p} 11$, the spectrin $\beta$ (SPTB) gene on chromosome 14q23, the spectrin $\alpha$ erythrocytic 1 (SPTA1) gene on chromosome 1q21, the solute carrier family 4 member 1 (SLC4A1) gene on chromosome 17q21, and the erythrocyte membrane protein band 4.2 (EPB42) gene on chromosome $15 \mathrm{q} 15$. The advent of whole-exome sequencing (WES) has made molecular diagnosis of hereditary erythrocyte membrane defects, including HS, feasible [5, 6]. However, molecular analysis of the affected genes has not been recommended as one of the routine diagnostic approaches by current HS guidelines [2].

Here, we present an HS family in which two diseasecausing mutations, SPTB c.C4873T and SLC4A1 c.G1469A, were identified separately in different individuals. In this family, there was no correlation between genotype and phenotype: the individuals harboring the same pathogenic gene mutation presented with different manifestations, while the individuals who presented with similar clinical features harbored different pathogenic mutations. The analysis of pathogenic gene mutations played an indispensable role in the accurate diagnosis and genetic counseling of this family.

\section{Case presentation}

Proband D, a 26-year-old man, complained of recurrent jaundice for 8 years and splenomegaly for more than 6 years. Physical examination revealed cutaneous and icteric sclera; the spleen was palpable $60 \mathrm{~mm}$ below the costal margin. His serum total bilirubin (TBIL) was $73.1 \mu \mathrm{mol} / \mathrm{l}$ and his direct bilirubin (DBIL) was $7.3 \mu \mathrm{mol} / \mathrm{l}$. The complete blood count revealed hemoglobin $125 \mathrm{~g} / \mathrm{l}$, reticulocytes $0.334 \times 10^{12} / \mathrm{l}$, mean corpuscular volume
(MCV) $85.7 \mathrm{fl}$, mean corpuscular hemoglobin (MCH) $28.4 \mathrm{pg}$ and $\mathrm{MCHC} 332 \mathrm{~g} / \mathrm{l}$, and spherocytes accounted for $13.6 \%$ of red blood cells (RBCs). Abdominal ultrasonography detected cholelithiasis in addition to splenomegaly. Serum hepatitis B virus surface antigen was positive, while liver biopsy showed no cirrhosis (Table 1).

Proband W, a 24-year-old girl, was diagnosed with HS complicated with jaundice and cholelithiasis and underwent cholecystectomy and splenectomy less than 5 years ago. Before the operation, her spleen was palpable $100 \mathrm{~mm}$ below the costal margin. Her serum TBIL was $74.0 \mu \mathrm{mol} / \mathrm{l}$, and her DBIL was $19.4 \mu \mathrm{mol} / \mathrm{l}$. The complete blood count revealed hemoglobin $114 \mathrm{~g} / \mathrm{l}$, reticulocytes $0.373 \times 10^{12} / \mathrm{l}$, MCV $79.8 \mathrm{fl}, \mathrm{MCH} 29.9 \mathrm{pg}$ and $\mathrm{MCHC} 374 \mathrm{~g} / \mathrm{l}$. Spherocytes accounted for $15.0 \%$ of RBCs (Table 1). She was re-evaluated clinically. Her TBIL was $27.3 \mu \mathrm{mol} / \mathrm{l}$, and her DBIL was $7.3 \mu \mathrm{mol} / \mathrm{l}$. Her hemoglobin was $163 \mathrm{~g} / \mathrm{l}$, reticulocytes was $0.081 \times$ $10^{12} / \mathrm{l}, \mathrm{MCV}$ was $88.4 \mathrm{fl}, \mathrm{MCH}$ was $32.0 \mathrm{pg}$, and $\mathrm{MCHC}$ was $364 \mathrm{~g} / \mathrm{l}$. Spherocytes accounted for $30.0 \%$ of RBCs (Table 1).

Proband D and proband $\mathrm{W}$ are cousins (their mothers are sisters). Of the proband W's immediate family members, splenomegaly and elevated reticulocytes, spherocytes and serum bilirubin were detected in her mother and brother. Her mother's spleen was palpable $32 \mathrm{~mm}$ below the costal margin. Her TBIL was $31.7 \mu \mathrm{mol} / \mathrm{l}$, and her DBIL was $12.6 \mu \mathrm{mol} / \mathrm{l}$. her was hemoglobin $114 \mathrm{~g} / \mathrm{l}$, reticulocytes was $0.145 \times 10^{12} / \mathrm{l}, \mathrm{MCV}$ was $84.7 \mathrm{fl}, \mathrm{MCH}$ was $30.1 \mathrm{pg}$ and $\mathrm{MCHC}$ was $355 \mathrm{~g} / \mathrm{l}$. Spherocytes accounted for $19.6 \%$ of RBCs. Her brother's spleen was palpable 27 $\mathrm{mm}$ below the costal margin. His TBIL was $29.2 \mu \mathrm{mol} / \mathrm{l}$, and his DBIL was $12.1 \mu \mathrm{mol} / \mathrm{l}$. his hemoglobin was $150 \mathrm{~g} / \mathrm{l}$, reticulocytes was $0.188 \times 10^{12} / \mathrm{l}, \mathrm{MCV}$ was $92.5 \mathrm{fl}, \mathrm{MCH}$ was $33.0 \mathrm{pg}$, and MCHC was $356 \mathrm{~g} / \mathrm{l}$. Spherocytes accounted for $18.0 \%$ of RBCs. In addition, slightly elevated reticulocytes $\left(0.138 \times 10^{12} / \mathrm{l}\right)$, serum bilirubin (TBIL19.3 $\mu \mathrm{mol} / \mathrm{l})$ and spherocytes $(10.0 \%$ of RBCs) also existed in proband W's father, while his spleen was not enlarged (details in Table 1).

However, no splenomegaly was found in proband D's immediate family members. Only slightly elevated reticulocytes $\left(0.084 \times 10^{12} / \mathrm{l}\right)$ and spherocytes $(8.0 \%$ of RBCs) were detected in his father. No HS clinical features or laboratory findings, such as spherocytes, raised $\mathrm{MCHC}$ or reticulocytosis, were found in his mother, who is the sister of proband W's mother (details in Table 1).

Proband D's father was also discovered to be a hepatitis B virus (HBV) carrier. Elevated serum lactate dehydrogenase (LDH) (307.4 U/L) was detected only in proband W's brother but not in any other family members (Table 1).

Peripheral vein blood was drawn from the probands and their immediate family members after they signed 
Table 1 Clinical and genetic features of proband D, proband $W$ and their immediate family members

\begin{tabular}{|c|c|c|c|c|c|c|c|c|c|}
\hline & $\begin{array}{l}\text { proband D } \\
\text { before } \\
\text { splenectomy }\end{array}$ & $\begin{array}{l}\text { proband D } \\
\text { after } \\
\text { splenectomy }\end{array}$ & $\begin{array}{l}\text { proband } \\
\text { D's father }\end{array}$ & $\begin{array}{l}\text { proband } \\
\text { D's mother }\end{array}$ & $\begin{array}{l}\text { proband W } \\
\text { before } \\
\text { splenectomy }\end{array}$ & $\begin{array}{l}\text { proband W } \\
\text { after } \\
\text { splenectomy }\end{array}$ & $\begin{array}{l}\text { proband } \\
\text { W's father }\end{array}$ & $\begin{array}{l}\text { proband } \\
\text { W's mother }\end{array}$ & $\begin{array}{l}\text { proband } \\
\text { W's brother }\end{array}$ \\
\hline Age $(Y)$ & 25 & 26 & 50 & 49 & 20 & 24 & 48 & 48 & 18 \\
\hline Sex & M & M & M & F & $\mathrm{F}$ & F & M & $\mathrm{F}$ & M \\
\hline Spleen (mm below rib) & 60 & / & $\begin{array}{l}\text { Not } \\
\text { palpable }\end{array}$ & $\begin{array}{l}\text { Not } \\
\text { palpable }\end{array}$ & 100 & / & $\begin{array}{l}\text { Not } \\
\text { palpable }\end{array}$ & 32 & 27 \\
\hline Cholelithiasis & Y & / & $\mathrm{N}$ & $\mathrm{N}$ & Y & / & N & N & N \\
\hline HBV carrier & Y & Y & Y & N & $\mathrm{N}$ & $\mathrm{N}$ & N & NA & N \\
\hline $\mathrm{HB}(\mathrm{g} / \mathrm{l})$ & 125 & 181 & 152 & 125 & 114 & 163 & 159 & 114 & 150 \\
\hline MCV (fl) & 85.7 & 83.7 & 88.7 & 91.4 & 79.8 & 88.4 & 91.2 & 84.7 & 92.5 \\
\hline $\mathrm{MCH}(\mathrm{pg})$ & 28.4 & 27.1 & 29.2 & 29.9 & 29.9 & 32.0 & 31.2 & 30.1 & 33.0 \\
\hline $\mathrm{MCHC}(\mathrm{g} / \mathrm{l})$ & 332 & 323 & 329 & 327 & 374 & 364 & 343 & 355 & 356 \\
\hline $\operatorname{Ret}\left(\times 10^{12} / \mathrm{l}\right)$ & 0.334 & NA & 0.084 & 0.061 & 0.373 & 0.081 & 0.138 & 0.145 & 0.188 \\
\hline Spherocyte (\%) & 13.6 & NA & 8 & 1 & 15 & 30 & 10 & 19.6 & 18 \\
\hline TBIL $(\mu \mathrm{mol} / \mathrm{l})$ & 73.1 & 19.1 & 12.8 & 7.6 & 74.0 & 27.3 & 19.3 & 31.7 & 29.2 \\
\hline DBIL $(\mu \mathrm{mol} / \mathrm{l})$ & 7.3 & 8.3 & 4.2 & 2.9 & 19.4 & 7.3 & 5.7 & 12.6 & 12.1 \\
\hline LDH (U/I) & 224.9 & NA & 239 & 171.9 & 226.4 & 869.9 & 254.4 & 188.7 & 307.4 \\
\hline $\begin{array}{l}\text { SPTB } \\
\text { c.4873 C> T } \\
\text { p.R1625X }\end{array}$ & & Y & $\mathrm{N}$ & $\mathrm{N}$ & & $\mathrm{N}$ & N & $N$ & $\mathrm{~N}$ \\
\hline $\begin{array}{l}\text { SLC4A1 } \\
\text { c. } 1469 G>A \\
\text { p. R490H }\end{array}$ & & N & N & N & & Y & $\mathrm{N}$ & Y & Y \\
\hline
\end{tabular}

$H B$ hemoglobin, $M C V$ mean corpuscular volume, $M C H$ mean corpuscular hemoglobin, $M C H C$ mean corpuscular hemoglobin concentration, Ret reticulocytes, TBIL total bilirubin, DBIL direct bilirubin, $L D H$ lactate dehydrogenase, SPTB spectrin $\beta$, SLC4A1 solute carrier family 4 member $1, M$ male, $F$ female, $Y$ Yes, $N$ No, NA not available

informed consents. The genomic DNA was extracted and the genomic DNA library was constructed according to Agilent's protocol. WES services were provided by the Chigene Bioinformatics Institute (Beijing, China) . Exomes were captured by Nimblegen kits, and nextgeneration sequencing (NES) was conducted with an Illumina HiSeq. The results were aligned to the University of California Santa Cruz, human genome assembly 19 (UCSC.hg19; http://genome.ucsc.edu/) reference sequence. VCFtools program of the SAMTools software, version 0.1 .16 (http://samtools.sourceforge.net/) was used to identify and call variants, including singlenucleotide polymorphisms (SNPs) and indels. ANNOVAR was used to annotate the variants. There are 48 , 747 variants and 49,276 variants were identified in proband $\mathrm{D}$ and proband $\mathrm{W}$ respectively. The strategies of data filtering were on the basis of the published documents $[7,8]$.

WES revealed that proband D was heterozygous for the c.C4873T (p.R1625X) mutation within exon 23 of SPTB, which were confirmed by Sanger sequencing of the polymerase chain reaction (PCR) products. Primers are as following: forward 5' - GGTCTCTCAAAGCTGGAATGA - 3', reverse 5' - AAATTGGTGCTCTCAGGTCA -3'. PCR products were sequenced and analyzed using Phred-
Phrap-Consed version 12.0 software (http://phrap.org/ phredphrapconsed.html). Sequencing results were compared with the reference sequences for SPTB (GenBank accession no. NM_001024858). Then, the detected mutations were searched in the 1000 Genomes Project database and Exome Aggregation (http://internationalgenome. org/1000-genomes-browsers). The SPTB R1625X mutation was not present in any of his immediate family members (Fig. 1). This mutation introduced a premature stop codon at amino acid residue 1625 , which created a truncated $\beta$-spectrin protein, and was predicted to be diseasecausing by the analytical software. The truncated protein lack of the ankyrin binding domain and the tetramerization domain has been proved to lead to inefficient incorporation of the mutant protein into the skeleton and result in HS (Fig. 2) [9-11]. In addition, it has been previously identified as a pathogenic mutation [12, 13]. Therefore, combined with the patient's clinical diagnosis of HS, the SPTB R1625X was identified as a pathogenic mutation, and was causative for HS development in proband D according to the American College of Medical Genetics (ACMG) guidelines [14]. The SPTB R1625X mutation was determined to be a de novo mutation in proband $\mathrm{D}$.

Meanwhile, WES revealed that proband W was heterozygous for the c.G1469A (p.R490H) mutation within exon 


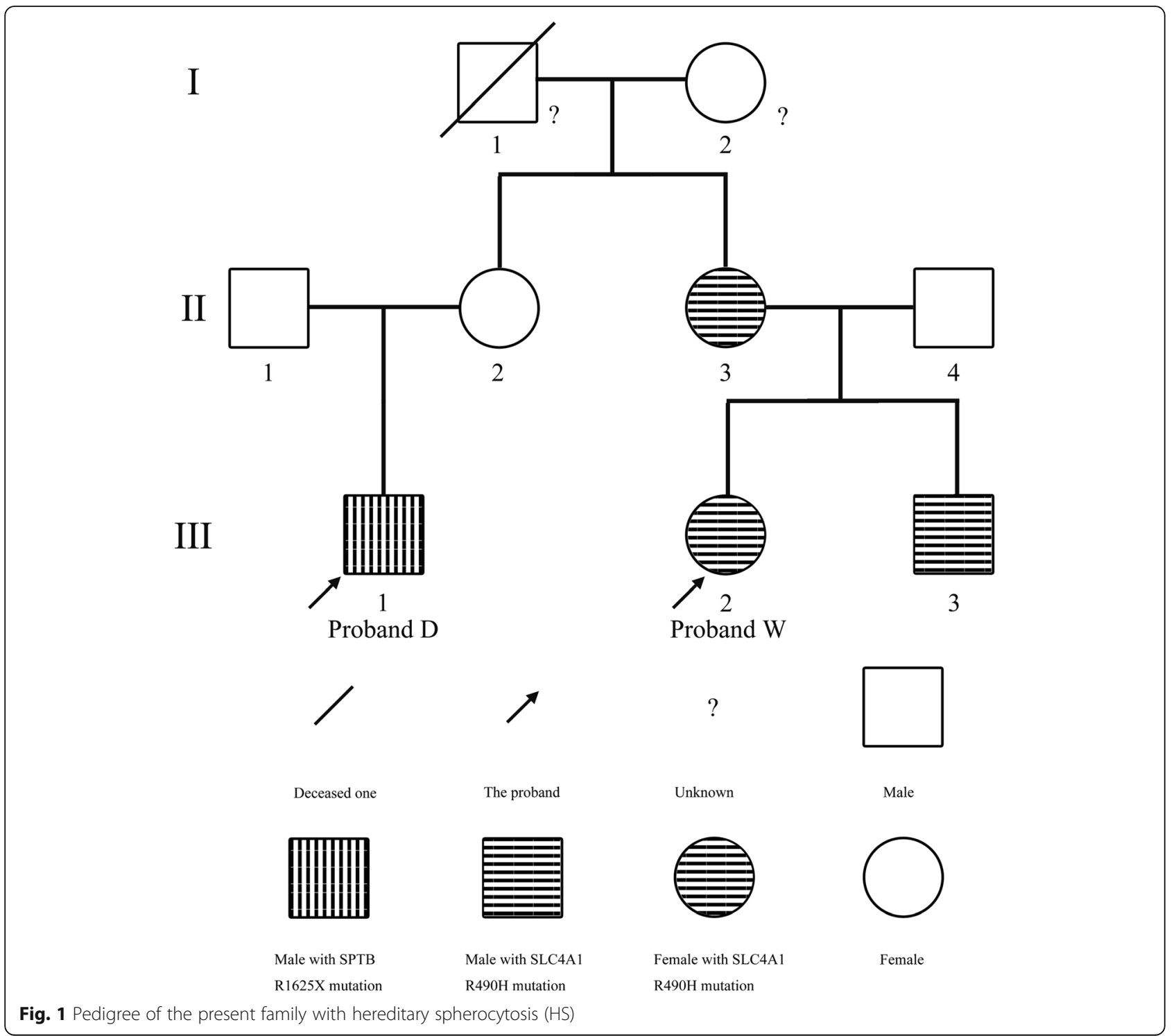

$\beta$-spectrin

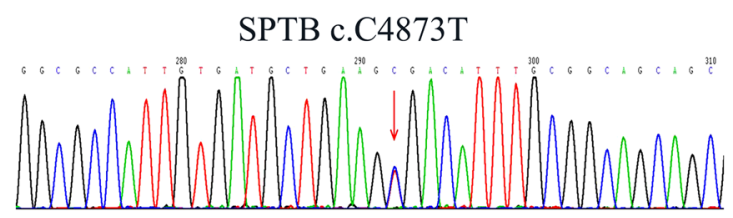

\begin{tabular}{|c|c|c|c|c|c|c|c|c|c|c|c|c|c|c|c|c|c|c|}
\hline CH & $\mathrm{CH}$ & 1 & 2 & 3 & 4 & 5 & 6 & 7 & 8 & 9 & 10 & 11 & 12 & $13^{*}$ & 14 & 15 & 16 & 17 \\
\hline $\begin{array}{r}\text { Actin } \\
\text { do }\end{array}$ & $\begin{array}{l}\text { ding } \\
\mathrm{n}\end{array}$ & & $\begin{array}{l}\text { zation } \\
\text { ain }\end{array}$ & & & & & arts o & pectr & repea & & & & & $\begin{array}{l}\text { Ankyri } \\
\text { dor }\end{array}$ & $\begin{array}{l}\text { inding } \\
\text { in }\end{array}$ & $\begin{array}{r}\text { Tetra } \\
\text { d }\end{array}$ & zatic \\
\hline
\end{tabular}

Fig. 2 Sanger sequencing of the pathogenic SPTB C.C4873T mutation in proband D and the localization of the mutation in schematic diagram of $\beta$-spectrin. A heterozygous c.C4873T (p.R1625X) mutation in SPTB gene, which encodes $\beta$-spectrin, was identified in proband D. Human erythroid $\beta$-spectrin molecule consists of two $\mathrm{N}$-terminal calponin homology $(\mathrm{CH})$ domains responsible for actin binding and seventeen $\beta$-spectrin repeats including dimerization domain (repeats 1 and 2), Ankyrin binding domain (repeats 14 and 15) and a tetramerization domain (repeats 16 and 17). The nonsense R1625X mutation was located on $\beta$-spectrin repeat 13. The red arrow indicates C4873T mutation detected in Sanger sequencing. The asterisk indicates the position of R1625X mutation in $\beta$-spectrin. SPTB, spectrin $\beta$ 
13 of SLC4A1, which was confirmed by Sanger sequencing of the PCR products. Primers for PCR were as following: forward 5'-TTGACTGACCGGCTTCTTCT-3', reverse 5'-AGGACACAATGGCTCAGTCT-3'. Sequencing results were compared with the reference sequences for SLC4A1 (GenBank accession no. NM_000342). The SLC4A1 R490H was also present in her mother and brother (Fig. 1). SLC4A1 gene codes band 3 protein, the predominant glycoprotein of RBCs membrane. Band 3 consists of 14 transmembrane (TM) segments and short helical $(\mathrm{H})$ segments linking TM segments. HS-related mutations are common in the TM segments. This mutation predicted a change from arginine to histidine at highly conserved amino acid residue 490, which was located at the $\mathrm{N}$-terminus boundary of the fourth putative TM segment of band 3, and the substitution could destabilize the helix and position of the segment in the bilayer of red blood cell membrane (Fig. 3) [15]. And the mutation was predicted to be disease-causing by the analytical software. In addition, it has been previously reported as a pathogenic mutation [16, 17]. Therefore, combined with the patient's clinical diagnosis of HS, SLC4A1 $\mathrm{R} 490 \mathrm{H}$ was probably as a pathogenic mutation and was causative for HS development in proband W, her mother and brother according to the ACMG guidelines [14].

In addition, with the combination of WES and Sanger sequencing, no additional genomic defects involved in HS-related symptoms, such as uridine diphosphate glucuronosyl transferase 1A1 (UGT1A1) deficiency involved in jaundice, have been detected in the whole family.

\section{Discussion and conclusions}

HS is a common hereditary hemolytic anemia with a heterogeneous phenotype that arises from reduced deformability due to defects in several cytoskeletal proteins, including ankyrin, $\alpha$ spectrin, $\beta$ spectrin, band 3 and protein 4.2 [1]. As HS pathogenic mutations involve five large-size genes, labor-intensive Sanger sequencing has been precluded for HS molecular diagnosis. In recent years, WES has shed new light on HS diagnosis and evaluation as a comprehensive and rapid diagnostic tool, especially in cases where traditional testing has failed, or was inconclusive, although WES has not been accepted as a routine diagnostic tool $[6,7,12,18]$.

In the present study, proband $\mathrm{D}$ and proband $\mathrm{W}$ presented with similar manifestations including jaundice,

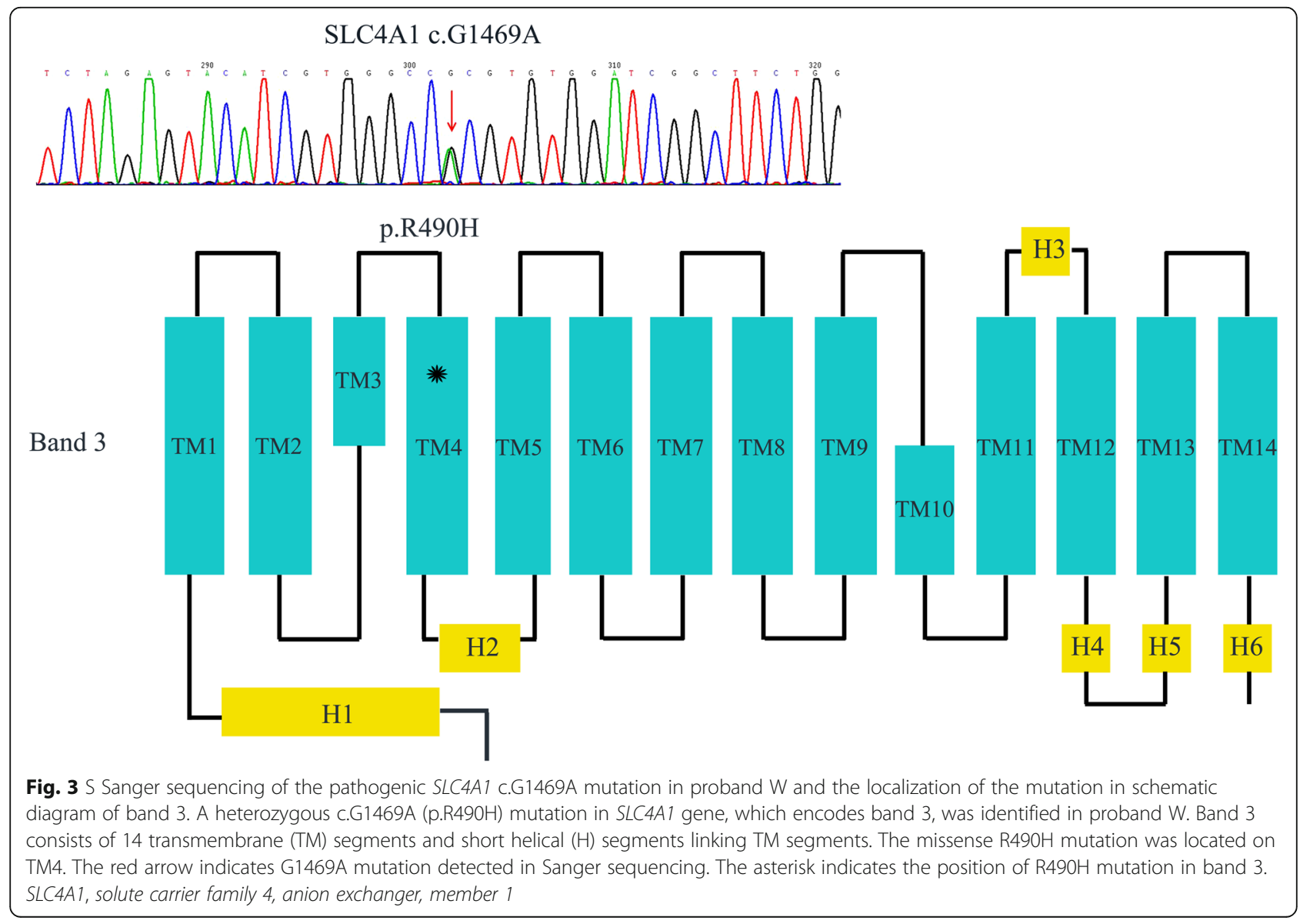


cholelithiasis and splenomegaly. Both probands underwent splenectomy and cholecystectomy. Since their mothers were sisters, their HS had been predicted to be inherited from their maternal side. In further clinical analysis, moderate HS manifestations were detected in proband W's mother and brother. However, no HS manifestations were found in proband D's mother, while the inconclusive values near cut-off points including reticulocyte, serum bilirubin and spherocytes, were also detected in healthy family members, proband W and proband D's fathers. Hence, according to the clinical data, the identification of HS individuals and the pattern of inheritance in this family was obscure.

To clarify the HS diagnosis and genetic model, WES was performed on samples from this family. Surprisingly, two different HS pathogenic mutations, SPTB c.C4873T and SLC4A1 c.G1469A, were identified in proband D and proband W separately. Furthermore, SPTB c.C4873T was confirmed as a de novo mutation in proband $\mathrm{D}$, while in proband W, HS was attributed to SLC4A1 c.G1469A and determined to be inherited from her mother and was also inherited by her brother. Other relatives were excluded as HS patients. Sanger sequencing confirmed the findings of WES. Notably, although proband W, her mother and brother shared the same pathogenic mutation, SLC4A1 c.G1469A, their clinical features were discrepant: proband W suffered from significant splenomegaly, jaundice and cholelithiasis, which incurred cholecystectomy and splenectomy; in her mother and brother, their HS was not complicated by cholelithiasis, and their splenomegaly and elevated serum bilirubin were moderate. Additional genomic defects involved in HS-related symptoms have not been detected in this family. And the reason of their clinical discrepancy is unknown.

In this family, analysis of clinical manifestations was not conclusive for the identification of HS individuals and the pattern of inheritance, while genetic analysis combined WES and Sanger sequencing provided accurate evidence for precise diagnosis, and clarified the complex genetic background of this family. Although current guidelines do not recommend genetic analysis for routine HS diagnosis, especially for newly diagnosed patients with a family history of HS [1], in our experience, HS presents with wide heterogeneity in clinical symptoms, and genetic analysis is a time- and costeffective method that gave a clear conclusion to the obscured individuals without typical clinical and laboratory features in this HS family. In particular, genetic analysis was indispensable for the identification of the pathogenic mutation and pattern of inheritance and could sometimes unveil unexpected pathogenic evidence, which is also very meaningful for investigating the precise underlying pathophysiologic mechanism of HS individuals or families.
In addition, according to published mutations of pathogenic HS genes, there are no hotspot mutations, and most mutations are sporadic [19]. Studies on genotype-phenotype relationships of HS have been attempted [10, 16]. However, no definite conclusions have been drawn. Moreover, because HS is an autosomal dominant genetic disease, de novo mutations should not be rare in HS. Hence, analysis of the pathogenic mutations of HS is complex. WES is a comprehensive and invaluable diagnostic tool that overcomes the limitations of the detection capability of Sanger sequencing, making the thorough and individualized evaluations of specific HS individuals feasible. In addition, during interpretation on the pathogenicity of the mutations detected by WES, ACMG guidelines should be followed rigorously to avoid incorrect interpretation of HS-related gene mutations, and provide precise diagnosis and genetic consultation for HS patients and their family members.

In conclusion, de novo SPTB c.C4873T mutation and inherited the $S L C 4 A 1$ c.G1469A were identified separately, in the present HS family. Moreover, the individuals harboring the same pathogenic gene mutation presented with different manifestations, while the individuals who presented with similar clinical features harbored different pathogenic mutations. Our findings suggested that both genotypes and phenotypes could be heterogeneous in the same HS family. The analysis of pathogenic gene mutations combined WES and Sanger sequencing is a time- and cost-effective method that may endeavor to play an indispensable role in the accurate diagnosis and genetic consultation of HS individuals and their family members.

\section{Abbreviations}

ACMG: American College of Medical Genetics; ANK1: Ankyrin 1; DBIL: Direct bilirubin; EPB42: Erythrocyte membrane protein band 4.2; H: Helical; HBV: Hepatitis B virus; HS: Hereditary spherocytosis; LDH: Lactate dehydrogenase; MCH: Mean corpuscular hemoglobin; MCHC: Mean corpuscular hemoglobin concentration; MCV: Mean corpuscular volume; PCR: Polymerase chain reaction; RBCs: Red blood cells; SLC4A1: Solute carrier family 4 member 1; SNPS: Single-nucleotide polymorphisms; SPTA1: Spectrin a erythrocytic 1; SPTB: Spectrin $\beta$; TBIL: Total bilirubin; TM: Transmembrane; UGT1A1: Uridine diphosphate glucuronosyl transferase 1A1; WES: Wholeexome sequencing

\section{Funding}

This study was supported by the National Natural Science Foundation of China (grant no. 81100360) in the design of the study and collection of the data; by Natural Science Foundation of Hunan province (grant no. 2018JJ2562) in the analysis and interpretation of the data and in writing the manuscript.

\section{Availability of data and materials}

The datasets generated during and/or analysed during the current study are not publicly available. However, datasets are available from the

corresponding author on reasonable request.

\section{Authors' contributions}

$\mathrm{HS}$ performed the experiments. $\mathrm{HH}$ and $\mathrm{KL}$ collected the clinical details and samples of the patient. XS and YY designed the research, and were principal 
investigators with primary responsibility for the paper. YY drafted the article. All authors critically revised the manuscript and contributed to the discussion. The final version of the paper was read and approved by all authors.

\section{Ethics approval and consent to participate}

Prior to participation, participants signed an informed consent form. The study was conducted in accordance with the Declaration of Helsinki II and was approved by Ethics Committee of The Second Xiangya Hospital of Central South University (Changsha, China).

\section{Consent for publication}

All participants signed informed consent for publication.

\section{Competing interests}

The authors declare that they have no competing interests.

\section{Publisher's Note}

Springer Nature remains neutral with regard to jurisdictional claims in published maps and institutional affiliations.

\section{Author details}

${ }^{1}$ Central Lab, The Second Xiangya Hospital, Central South University, Changsha, Hunan Province, People's Republic of China. ${ }^{2}$ Department of Medical Genetics, The Second Xiangya Hospital, Central South University, Changsha, Hunan Province, People's Republic of China. ${ }^{3}$ Department of Infectious Diseases, The Second Xiangya Hospital, Central South University, Changsha, Hunan Province, People's Republic of China. ${ }^{4}$ Department of Hematology, The Second Xiangya Hospital, Central South University, 139 Middle Renmin Road, Changsha, Hunan Province 410011, People's Republic of China. ${ }^{5}$ Department of Medical Genetics, The Second Xiangya Hospital, Central South University, 139 Middle Renmin Road, Changsha, Hunan Province 410011, People's Republic of China.

\section{Received: 17 February 2019 Accepted: 16 May 2019}

Published online: 24 May 2019

\section{References}

1. Perrotta S, Gallagher PG, Mohandas N. Hereditary spherocytosis. Lancet. 2008:372:1411-26.

2. Bolton-Maggs PH, Langer JC, lolascon A, Tittensor P, King MJ, General Haematology Task Force of the British Committee for Standards in Haematology. Guidelines for the diagnosis and management of hereditary spherocytosis--2011 update. Br J Haematol. 2012;156:37-49.

3. Yi Y, Dang X, Li Y, Zhao C, Tang H, Shi X. Genetic diagnosis and pathogenic analysis of an atypical hereditary spherocytosis combined with UGT1A1 partial deficiency: A case report. Mol Med Rep. 2018;17:382-7.

4. Ma S, Deng X, Liao L, Deng Z, Qiu Y, Wei H, et al. Analysis of the causes of the misdiagnosis of hereditary spherocytosis. Oncol Rep. 2018:40:1451-8.

5. Andolfo I, Russo R, Gambale A, lolascon A. New insights on hereditary erythrocyte membrane defects. Haematologica. 2016;101:1284-94.

6. He Y, Jia S, Dewan RK, Liao N. Novel mutations in patients with hereditary red blood cell membrane disorders using next-generation sequencing. Gene. 2017:627:556-62

7. Lin PC, Chiou SS, Lin CY, Wang SC, Huang HY, Chang YS, et al. Wholeexome sequencing for the genetic diagnosis of congenital red blood cell membrane disorders in Taiwan. Clin Chim Acta. 2018;487:311-7.

8. Fan LL, Liu JS, Huang H, Du R, Xiang R. Whole exome sequencing identified a novel mutation (p.Ala1884Pro) of $\beta$-spectrin in a Chinese family with hereditary spherocytosis. J Gene Med. 2019;21:e3073.

9. Sriswasdi S, Harper SL, Tang HY, Gallagher PG, Speicher DW. Probing large conformational rearrangements in wild-type and mutant spectrin using structural mass spectrometry. Proc Natl Acad Sci U S A. 2014;111:1801-6.

10. Park J, Jeong DC, Yoo J, Jang W, Chae H, Kim J, et al. Mutational characteristics of ANK1 and SPTB genes in hereditary spherocytosis. Clin Genet. 2016;90:69-78.

11. Hassoun H, Vassiliadis JN, Murray J, Yi SJ, Hanspal M, et al. Molecular basis of spectrin deficiency in beta spectrin Durham. A deletion within beta spectrin adjacent to the ankyrin-binding site precludes spectrin attachment to the membrane in hereditary spherocytosis. J Clin Invest. 1995;96:2623-9.
12. Agarwal AM, Nussenzveig RH, Reading NS, Patel JL, Sangle N, Salama ME, et al. Clinical utility of next-generation sequencing in the diagnosis of hereditary haemolytic anaemias. Br J Haematol. 2016;174:806-14.

13. Muramatsu H, Okuno Y, Yoshida K, Shiraishi Y, Doisaki S, Narita A, et al. Clinical utility of next-generation sequencing for inherited bone marrow failure syndromes. Genet Med. 2017;19:796-802.

14. Richards S, Aziz N, Bale S, Kulkarni S, Lindeman NI, Roy S, et al. Standards and guidelines for the interpretation of sequence variants: a joint consensus recommendation of the American College of Medical Genetics and Genomics and the Association for Molecular Pathology. Genet Med. 2015; 17:405-23.

15. Reithmeier RA, Casey JR, Kalli AC, Sansom MS, Alguel Y, Iwata S. Band 3, the human red cell chloride/bicarbonate anion exchanger (AE1, SLC4A1), in a structural context. Biochim Biophys Acta. 2016;1858:1507-32.

16. Dhermy D, Galand C, Bournier O, Boulanger L, Cynober T, Schismanoff $\mathrm{PO}$, et al. Heterogenous band 3 deficiency in hereditary spherocytosis related to different band 3 gene defects. Br J Haematol. 1997;98:32-40.

17. Lima PR, Sales TS, Costa FF, Saad ST. Arginine 490 is a hot spot for mutation in the band 3 gene in hereditary spherocytosis. Eur J Haematol. 1999;63: 360-1.

18. Russo R, Andolfo I, Manna F, Gambale A, Marra R, Rosato BE, et al. Multigene panel testing improves diagnosis and management of patients with hereditary anemias. Am J Hematol. 2018;93:672-82.

19. He BJ, Liao L, Deng ZF, Tao YF, Xu YC, Lin FQ. Molecular Genetic Mechanisms of Hereditary Spherocytosis: Current Perspectives. Acta Haematol. 2018;139:60-6.

\section{Ready to submit your research? Choose BMC and benefit from:}

- fast, convenient online submission

- thorough peer review by experienced researchers in your field

- rapid publication on acceptance

- support for research data, including large and complex data types

- gold Open Access which fosters wider collaboration and increased citations

- maximum visibility for your research: over $100 \mathrm{M}$ website views per year

At $\mathrm{BMC}$, research is always in progress.

Learn more biomedcentral.com/submissions 